\title{
We and They: Pronouns as Measures of Political Identification and Estrangement ${ }^{1}$
}

\author{
M. RICHARD CRAMER \\ University of North Carolina at Chapel Hill
}

and

HOWARD SCHUMAN ${ }^{2}$

University of Michigan

\begin{abstract}
Some people refer to the United States government as "we," some people as "they," in responses to an open-ended survey question on American intervention in Vietnam. This seemingly trivial linguistic difference (and perhaps others) can be included as part of a regular coding operation. In the present instance, race seems to be the most important determinant of pronoun usage, with blacks more likely to refer to the United States as "they" rather than "we." The pattern of other associations to pronoun referent also differs by race: white they-sayers tend to be low in education and in personal trust of other people generally, while black they-sayers are not distinctive in education, but give evidence of solidarity with blacks and of alienation from whites. Not all the results fit together neatly, and limitations of the present measure are noted, but the findings suggest the value of content analysis of linguistic style in verbatim responses to survey questions.
\end{abstract}

This paper explores the use of responses to open-ended survey questions in a relatively simple but unfamiliar way: to code for substantive implication the basic linquistic categories by which people express themselves. Specifically, we examine the occurrence and correlates of the pronouns "we" and "they"

${ }^{1}$ Authors' names in alphabetical order. We are indebted to the Detroit Area Study and to Otis Dudley Duncan, DAS Faculty Participant in 1971; to Elizabeth Fischer and Susan Mortimer, who helped in code construction and coding; and to Stanley Presser, who provided useful suggestions and assistance at several points. Support for analysis came in part from grants to Schuman from NIMH (MH 24266) and NSF (GS 39780). An earlier version of the paper was given at the American Sociological Association meetings, Montreal, 1974.

2 Address correspondence to Professor Howard Schuman, Institute for Social Research, University of Michigan, Ann Arbor, MI 48104. 
in referring to a major governmental action. The choice of pronoun appears to be a manifestation, though not a wholly conscious one we assume, of identification or failure to identify with governing institutions. The paper is essentially an attempt to assess the value and limitations of such a measure. That there are limitations will become obvious, but the possibility of drawing in survey research on the natural linguistic categories by which people communicate with one another encourages us to present this tentative set of results. As Brown and Gilman (1960) have shown in another context, parts of speech generally taken for granted can reflect and convey important meaning about a person's position in the larger society.

\section{SOURCE OF DATA}

Data were gathered in the summer of 1971 through a Detroit Area Study cross-section probability sample of 1,881 persons, 21 years of age and over, in metropolitan Detroit. ${ }^{3}$ Although primarily a replication study concerned with long-term change, the 1971 survey included a question about attitudes toward recent American involvement in Vietnam: "In view of the developments since we entered the fighting, do you think the United States made a mistake in sending troops to fight in Vietnam?" About two-thirds of the respondents $(N=1,280)$ answered affirmatively. These persons were then asked by open-ended question to explain their answers: "Why would you say it was a mistake?" It is from spontaneous replies to this open-ended question (and additional nondirective probes) that we are able to classify respondents according to their use of only "we," only "they," both pronouns, or neither in their reference to the United States government. Focusing on only the two more interpretable categories, "we" and "they," in Table 1, we can observe

TABLE 1

Use of Personal Pronouns in Response to Open Question on Vietnam ${ }^{a}$

\begin{tabular}{|c|c|c|}
\hline \multirow[b]{2}{*}{ Refers to U.S. government as "we" } & \multicolumn{2}{|c|}{$\begin{array}{c}\text { Percentage } \\
\text { distributions }\end{array}$} \\
\hline & 56.5 & 81.7 \\
\hline Refers to U.S. government as "they" & 12.6 & 18.3 \\
\hline Uses both "we" and "they" & 8.4 & - \\
\hline \multirow[t]{2}{*}{$R$ does not refer to U.S. government as either "we" or "they" } & 22.5 & -- \\
\hline & 100.0 & 100.0 \\
\hline$N$ & $(1280)$ & $(885)$ \\
\hline
\end{tabular}

aThe open question was asked only of the $68 \%$ of the original sample $(N=1,881)$ who had previously indicated that U.S. involvement in Vietnam was a mistake.

${ }^{3}$ For further information on sampling, see Fischer (1972). 
that $82 \%$ of the combined set are classified as "we-sayers" and $18 \%$ as "they-sayers." Our aim is to determine whether this grammatical distinction reflects a political difference.

We-saying was the modal response for our samplc and was generally easy to code. Examples, with codable pronouns italicized are:

It's our own fault we are in a mess over there. We could clean up that mess if we wanted to. It was the same in Korea. We were afraid of getting into a war with Red China or Russia.

Because the war in Vietnam does not concern $u s$ and we should not have entered. (Probe) Well, there's so many things in this country all of that money could have bought.

As noted, we included "our" and "us" as codable responses when they seemed to have the same meaning as "we." No attempt was made to count the number of "we" (or "they") pronouns; a response was coded as an instance of we-saying if it had one or more uses of "we."

They-saying was not only much less frequent, but also more ambiguous. Our interest was in its use to refer to the United States government or to American society, but sometimes it was employed to refer to American soldiers, or to the Vietnamese, and sometimes the referent was simply not clear. Coding instructions, of course, aimed for the inclusion of only usages referring to the United States or the U.S. government. Examples of coded responses are:

Because I'm against the war. (Probe) I'm against war in general and specifically I don't think the States should have become directly involvedthey should have stayed out. (Probe) It's none of their business.

It has lasted much too long. I don't think they've gained too much and they've lost a lot of lives. They should fight it and get it over.

In the second response, each mention of "they" is somewhat ambiguous taken alone, but the combination is interpreted to refer to the U.S. government, especially in the context of the closed question that preceded the "wliy" inquiry.

The responses which did not involve use of either "we" or "they" included a large proportion in which the interviewer obviously omitted pronouns along with other "unimportant" words. 4 For purposes of our analysis, we make the not unreasonable assumption that such omissions are essentially unrelated to the various associations to be examined. A second problematic set of responses involved the small number which included both "we" and "they." Partial analysis using a three-point scale with we-they combinations as intermediate does not change our basic results (although it

$4_{\text {It }}$ should be noted that while interviewers were instructed generally to record responses verbatim, they were not told explicitly to note the use of "we" or "they." The idea of the we-they distinction did not emerge until after the ficld work, although before the data were coded or analyzed in any way. 
generally weakens associations slightly), and we present here the simpler analysis employing two categories only-pure we-sayers and pure they-sayers.

Coding of the responses was carried out by a single coder, after several hours of discussion and practice with one of the authors. A second, relatively untrained person check-coded a random subsample of 100 responses, and achieved a $90 \%$ agreement with the main coder. Unfortunately, reliability of respondents themselves over time is not so high: 60 respondents gave "we" or "they" responses to the same questions by telephone several months after the original interview, and there is only a small and nonsignificant trend for pronoun usage to be consistent across the two occasions. This finding, which may be due to reliance on a single question for the coding and to the small number of cases in the reinterview survey, emphasizes the tentative nature of this report. Yet some of the associations among categories to be discussed are so strong as to make it very doubtful that they could have occurred by chance, despite the lack of strong evidence of stability over time at the individual level. If even in the crude and rather unreliable form that we are using, the measure relates to other indicators of disaffection, estrangement, or alienation from the government, further experimentation with this type of coding in survey research seems warranted.

\section{ASSOCIATIONS WITH BACKGROUND VARIABLES}

Table 2 summarizes relationships between several standard background variables and pronoun choice. What we are looking for here is evidence that the use of "they" to refer to the government is more common within segments of the population that might be expected to be less involved in or more hostile towards the mainstream of the political process.

Indeed, this is clearly the case for race. As seen in Table 2, there is a sizable and highly significant difference in the proportions of blacks and whites using "they." While the majority in both groups used the first-person pronoun, over a third of the blacks but fewer than one-seventh of the whites said "they." Thus it would appear, if we interpret the pronouns literally, that blacks identify less with the government than do whites, at least in the Detroit population. We will return below to the interpretation of this finding. But since race is the strongest correlate of the we-they coding, and probably the most meaningful one, we include it as a control in all further analysis.

Next to race, the most reliable correlate of they-saying is low education, though this turns out to be true only for whites. The absence of a similar relation for blacks may well reflect disproportionate they-saying among highly educated black respondents, rather than a lowering of it among the least educated: All black educational levels use "they" to an extent well above the highest white levels. Moreover, at the same time that the objective social 
TABLE 2

Relationships Between Background Variables and Pronoun Choice

\begin{tabular}{|c|c|c|c|c|c|}
\hline Variable & $x^{2}$ & $\mathrm{df}$ & $\operatorname{gamma}^{a}$ & $\begin{array}{l}\text { More } \\
\text { "they" }\end{array}$ & $\begin{array}{c}\text { Summary of } \\
\text { findings: \% "they" }\end{array}$ \\
\hline Race & $48.7 * *$ & 1 & 0.56 & Blacks & $\begin{array}{l}35 \% \text { of blacks (base } N=196) \\
13 \% \text { of whites }(N=687)\end{array}$ \\
\hline Education & $14.8^{* *}$ & 4 & 0.21 & Low ed. & $\begin{array}{l}21 \% \text { of } 0-8 \mathrm{yr} \text { of ed.; } 12 \% \text { of } \\
16+\mathrm{yr} \text { of ed. }\end{array}$ \\
\hline for blacks & 3.6 & 4 & 0.07 & - & No clear trend \\
\hline for whites & $11.1 *$ & 4 & 0.20 & Low ed. & $14 \%$ of $0-8 \mathrm{yr} ; 8 \%$ of $16+y r$ \\
\hline Age & 3.3 & 3 & 0.11 & Younger & $22 \%$ of $21-30 ; 16 \%$ of $60+$ \\
\hline for blacks & 2.8 & 3 & 0.17 & Younger & $40 \%$ of $21-30 ; 29 \%$ of $60+$ \\
\hline for whites & 0.2 & 3 & 0.03 & - & No clear trend \\
\hline Social class ident. & $4.6^{*}$ & 1 & 0.19 & $\begin{array}{l}\text { Working } \\
\text { class }\end{array}$ & $\begin{array}{l}21 \% \text { of working and lower; } \\
15 \% \text { middle and upper }\end{array}$ \\
\hline for blacks & 2.1 & 1 & 0.26 & $\begin{array}{l}\text { Working } \\
\text { class }\end{array}$ & $\begin{array}{l}38 \% \text { of working and lower; } \\
26 \% \text { of middle and upper }\end{array}$ \\
\hline for whites & 0.1 & 1 & 0.04 & - & No clear trend \\
\hline Family income & 3.6 & 5 & 0.07 & - & No clear trend \\
\hline for blacks & 5.4 & 5 & 0.08 & - & No clear trend \\
\hline for whites & 2.9 & 5 & 0.00 & - & No clear trend \\
\hline Sex & 1.3 & 1 & 0.10 & Men & $20 \%$ of men; $17 \%$ of women \\
\hline for blacks & 1.1 & 1 & 0.16 & Men & $40 \%$ of men; $32 \%$ of women \\
\hline for whites & 1.0 & 1 & 0.11 & Men & $15 \%$ of men; $12 \%$ of women \\
\hline Party preference & $6.4^{*}$ & 1 & 0.24 & Democrats & $\begin{array}{l}20 \% \text { of Democrats; } 14 \% \text { of } \\
\text { Republicans }\end{array}$ \\
\hline for blacks & 0.0 & 1 & 0.00 & - & No clear trend \\
\hline for whites & 0.4 & 1 & 0.07 & - & No clear trend \\
\hline
\end{tabular}

a Signs deleted.

$* * 0.01$ level of significance.

${ }^{*} 0.05$ level of significance.

class indicator of education is a correlate of white they-saying, subjective class identification provides a correlate of pronoun use among blacks only. Since there is evidence elsewhere (cf., Schuman and Hatchett, 1974) that lower class identification among blacks is associated with racial militancy, we suspect that the two class indicators point to different bases for they-saying among blacks and whites, respectively. This hypothesis will receive further support below when we turn to attitudinal correlates of pronoun usage.

The other associations in Table 2 are either nonsignificant or probably spurious. However, the trend for young blacks to use "they" more than their elders fits our tentative interpretation of black pronoun usage as especially 
political in character, since age is regularly found to be a correlate of black militancy (Caplan, 1970). Examination of both age and education together for both races fails to reveal any non-additive patterning of the two variables different from their separate effects in Table 2. The relation of sex to they-saying appears too slight to justify interpretation, while the statistical significance of party preference is apparently due to the fact that almost all Detroit blacks, but only about half the whites, are Democrats. The weakest of all correlates in the table is family income, indicating that not all aspects of social class are implicated in the associations discussed earlier.

One other variable could be introduced experimentally because our survey had manipulated race-of-interviewer for random subsamples of black respondents. There is no evidence, however, of such interviewer effects: the difference in pronoun choice by race-of-interviewer is trivial in size and far from significant $\left(\chi^{2}(1)=0.51\right)$. White interviewers obtain and record the same pronoun usage for black respondents as do black interviewers. Since race-ofinterviewer does influence conventional measures of racial attitudes (cf., Schuman and Hatchett, 1974), the lack of such effects on pronoun usage suggests that respondents are not themselves aware of the significance of "we" as against "they" in their speech.

In sum, the main they-sayers in our sample are blacks, and especially black youth. Among whites, they-saying is a phenomenon associated with lower education, though not with low income or with self-identification as outside the middle class. Since in the next section we will provide estimates of explained variation in dependent variables, it may be helpful here to note that race, our strongest predictor, accounts for $5.5 \%\left(E^{2}\right)$ of the variation in pronoun usage.

\section{ATTITUDINAL VARIABLES}

Table 3 presents the relationships between three composite attitude indexes and the we-they classification. Among blacks the evidence is strong that the pronoun distinction is an indicator of alienation from the larger white American society. Employing an index that has been used extensively in previous analysis, we find that black they-sayers are significantly more alienated along racial lines than are black we-sayers. ${ }^{5}$ When age is controlled by cross-tabulation within three age categories $(21-30,31-49,50+)$, the association between racial alienation and pronoun usage is small among the two older age groups $\left(E^{2}<1.0 \%\right.$ for each) and relatively high among young adults (4.4\%). A similar control for education $(0-8,9-12,13+)$ produces more striking results: the we-they distinction accounts for $9 \%$ of the variation in racial alienation scores among Blacks with at least some college $(N=36)$, as correlates.

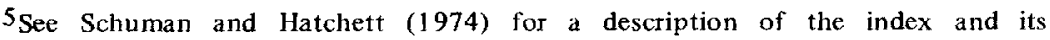


TABLE 3

Mean Scores for We- and They-Sayers on Attitude Indexes

\begin{tabular}{|c|c|c|c|c|c|c|c|c|c|}
\hline \multirow[b]{2}{*}{ Index } & \multirow[b]{2}{*}{ Sample } & \multicolumn{2}{|c|}{ We-sayers } & \multicolumn{2}{|c|}{ They-sayers } & \multirow[b]{2}{*}{$M_{2}-M_{1}$} & \multirow[b]{2}{*}{$E^{2}$} & \multirow[b]{2}{*}{$F$} & \multirow[b]{2}{*}{$P$} \\
\hline & & $M_{1}$ & $N$ & $M_{2}$ & $N$ & & & & \\
\hline $\begin{array}{r}\text { Black racial } \\
\text { alienation }\end{array}$ & Blacks & 4.1 & $(127)$ & 5.0 & (69) & 0.9 & $2.4 \%$ & 4.83 & 0.03 \\
\hline $\begin{array}{l}\text { Criticism of } \\
\text { government }\end{array}$ & $\begin{array}{l}\text { Total } \\
\text { Blacks } \\
\text { Whites }\end{array}$ & $\begin{array}{l}3.9 \\
4.2 \\
3.9\end{array}$ & $\begin{array}{l}(622) \\
(108) \\
(513)\end{array}$ & $\begin{array}{l}4.5 \\
4.8 \\
4.3\end{array}$ & $\begin{array}{r}(141) \\
(61) \\
(79)\end{array}$ & $\begin{array}{l}0.6 \\
0.6 \\
0.4\end{array}$ & $\begin{array}{l}1.1 \\
1.8 \\
0.4\end{array}$ & $\begin{array}{l}8.83 \\
3.16 \\
2.74\end{array}$ & $\begin{array}{l}0.01 \\
0.08 \\
0.10\end{array}$ \\
\hline Anomia & $\begin{array}{l}\text { Total } \\
\text { Blacks } \\
\text { Whites }\end{array}$ & $\begin{array}{l}5.1 \\
6.6 \\
4.7\end{array}$ & $\begin{array}{l}(716) \\
(127) \\
(588)\end{array}$ & $\begin{array}{l}5.6 \\
5.7 \\
5.4\end{array}$ & $\begin{array}{r}(157) \\
(68) \\
(88)\end{array}$ & $\begin{array}{r}0.5 \\
-0.9 \\
0.7\end{array}$ & $\begin{array}{l}0.6 \\
4.5 \\
0.9\end{array}$ & $\begin{array}{l}5.26 \\
9.26 \\
5.94\end{array}$ & $\begin{array}{l}0.02 \\
0.01 \\
0.02\end{array}$ \\
\hline
\end{tabular}

against $1.3 \%$ each among the grammar school educated $(N=44)$ and the high school educated $(N=112)$. Thus, the connection between they-saying and racial alienation is located among younger and especially among better educated blacks. (Unfortunately our black sample size does not permit adequate analysis of age and education simultaneously.)

On the hypothesis that they-saying reflects a more general lack of positive feelings toward government, we constructed a "Criticism of Government" index. Four three-point items about the performance of local and state levels of government and the federal courts were simply added together. (There were no parallel items available on the federal executive.) As Table 3 shows, the we-they coding is significantly related to negative attitudes toward these levels of government, a relationship that is located principally among blacks however. We know from other analyses that racial alienation and such criticism of government items are substantially correlated, so their similar relations to pronoun usage for blacks is not unexpected. What is surprising is that such criticism is a rather weaker correlate of they-saying among whites. Thus the most obvious political meaning of they-saying-negative feeling toward governing institutions-seems to be mainly a black phenomenon.

The pronouns "we" and "they" use the government as a referent, but also can be seen as expressing distance between the self and the larger society. With this in mind, we looked at the relation between pronoun choice and a four item Anomia scale dealing with distrust of other people. ${ }^{6}$ We hypothesized that they-sayers would show greater distance not only from government, but from other people generally. As Table 3 indicates, the hypothesis is

6 Two of the items are in agree-disagree form (e.g., "Most people don't really care what happens to the next fellow"). But two involve forced choice (e.g., "In general do you think that most people can be trusted, or do you feel that a person can't be too careful in his dealings with others?"). We-they usage shows the same trends for both formats. 
supported for whites (and for the total sample, in which whites predominate) but there is a strong and highly significant reversal for blacks. Those black who say "we" in reference to the total society are also high in distrust o other people on the Anomia index.

The result for whites might be thought due to the association of lor education with both they-saying and Anomia, but in fact when education $i$ controlled the (weighted) difference in means in Table 3 drops only from 0 . to 0.6 . Moreover, for blacks we find no reason to suspect a spurious source $\mathrm{c}$ the strong correlation in Table 3, so that a substantive interpretation seem called for. If we take our two measures seriously, then it appears that amon blacks a sense of identification with the national government (we-saying) associated with distrust of one's fellow man. Assuming that "fellow-men among black respondents are thought of largely as fellow black men an women, then what we may have here is an indication of the fundament: dilemma faced by blacks in a white-run society. To identify with the whit governing authorities involves social distance from others who are blact Racial identification and societal identification are at odds.

We offer this division-against-oneself interpretation with some hesit: tion, for we have no further way of validating it and such psychodynami types of reasoning are rarely supportable with survey data. What does seer clear is that the initial racial difference in they-saying is a deep one not likel to disappear with ordinary controls. If the 11-point racial alienation inde discussed above is cross-tabulated against pronoun usage, all levels of score have an incidence of they-saying well above that shown by whites. Blac they-saying is related to black racial sentiments and criticisms of the gover ment, but it goes beyond them and is manifested even by those who do ne show conscious militancy or alienation. Moreover, it is difficult to regar they-saying as simply a nonmeaningful trait of black speech, for we have sec that it does relate to attitude measures having face validity.

We have reported in Table 3 the clearest and most reliable attituc correlates of the we-they distinction. Two others that we examined did n yield such clear interpretations, yet must be reported for completeness. two-item index dealing with whether public officials "care about me"-one : original agree-disagree item, the other a reversal-shows only a weak trend $f_{1}$ black they-sayers to feel alienated from government in this sense $(P=0.0$ and no trend at all among whites. This is puzzling in light of the correlatiol reported earlier between we-they choice and criticisms of specific types , government officials.

More puzzling still is the relation of pronoun usage to a question abo possible American intervention to quell a "Communist uprising" in a Sou American country. We had hypothesized that they-sayers would be less like than we-sayers to support such intervention, but in fact they are more like to do so-the relationship reaching significance for whites $\left(\chi^{2}(1)=4\right.$. $P<0.03)$ and near-significance for blacks $\left(\chi^{2}(1)=3.4, P<0.07\right)$. This $w$ 
such a surprising result that it led to very careful checking for both errors in data processing and spurious factors, but neither type of explanation was discovered. We are left with a picture of they-sayers as less opposed to foreign intervention of the Vietnam type than are we-sayers. 7

\section{CONCLUSIONS}

Coding the pronouns "we" and "they" as indicative of identification or lack of identification with the government yields generally meaningful results. Use of "they" is much more frequent for blacks than for whites, and among blacks it is associated with other variables that suggest active estrangement from the government. Those blacks who do identify with the government as indicated by we-saying have significantly higher scores on an index of distrust of other people, presumably black people. For whites, they-saying is less strongly and consistently associated with other variables, but tends to accompany low education and distrust of other people. One gets the sense that black they-sayers visualize "they" vs "us," while for white they-sayers the image is "they" vs "me."

Although most of our results with the pronoun measure make good sense, not all do. And the measure as available here shows only a little reliability over time at the individual level. These limitations must make us hesitate to claim too much for it. But we do think the results promising enough to encourage further exploratory use of such linguistic coding by others interested in the content analysis of free responses to open questions. 8 Given accurate interviewer recording-obviously a sine qua non-pronoun or other linguistic coding is inexpensive and easy to introduce into survey analysis. If results prove useful, the measure offers the intrinsic value of dealing with the most basic categories by which people express themselves and communicate with one another.

7 One other possibility is that they-saying is tied to the kind of "win or get out" philosophy which led to disenchantment with the Vietnam war, but does not necessarily lead to reluctance to intervene elsewhere. Using a set of categories reported elsewhere (Schuman, 1972), we do find they-sayers slightly more likely to show such a win-or-getout opposition to Vietnam, thus warning against the assumption that use of "they" to refer to the United States implies a distinctively moral opposition to war. Nevertheless, controlling on such a variable does not reduce appreciably the initial association between they-saying and agreement to future American intervention in South America.

${ }^{8}$ We-they usage need not always turn on identification with the government as such. In Britain, "us" and "them" are often taken to refer to largely social class distinctions. In other cases special meaning is attached to the pronoun "we," as when President Ford was reported to identify so closely with Congress that in a New York speech "he apologized for repeatedly referring to the Congress as 'we' rather than 'it' or 'they"' (The New York Times, 1974). On the other hand, identification with a national collectivity can be expressed in other ways, as in the slow evolution of identity during the 18 th century of "British Americans" into "Americans" (Merritt, 1966). 


\section{REFERENCES}

Brown, R., and Gilman, A. (1960), "The pronouns of power and solidarity," in Style and Language (Thomas A. Sebeok, Ed.), pp. 253-276, MIT Press, Cambridge, MA.

Caplan, N. S. (1970), "The new ghetto man: A review of recent empirical studies," Journal of Social Issues, 26, 59-73.

Fischer, E. M. (1972), Sampling Report for the 1971 Detroit Area Study, Detroit Area Study, University of Michigan, Ann Arbor, MI.

Merritt, R. (1966), Symbols of American Community 1735-1775, Yale University Press, New Haven.

The New York Times, (1974), August 10, p. 40.

Schuman, H. (1972), "Two sources of antiwar sentiment in America," American Journal of Sociology, 78, pp. 513-536.

Schuman, H., and Hatchett, S. (1974), Black Racial Attitudes: Trends and Complexities, Institute for Social Research, Ann Arbor, MI. 